\title{
Análise comparativa dos modelos usados como ferramenta metodológica nas pesquisas sobre o Conhecimento Pedagógico de Conteúdo (PCK) de professores de Física no Brasil
}

\author{
Stela Silva Lima ${ }^{1}$ \\ Instituto Federal de Mato Grosso \\ Marta Maria Pontin Darsie ${ }^{1}$ \\ Universidade Federal de Mato Grosso \\ Geison Jader Mello ${ }^{l}$ \\ Instituto Federal de Mato Grosso \\ Cuiabá - MT
}

\section{Resumo}

A base de conhecimento de professores vem sendo objeto de pesquisas, em diversas áreas da educação, ao longo de muitas décadas, sendo abordada por diferentes perspectivas teóricas e autores, dentre os quais o conceito introduzido por Lee Shulman (1986; 1987), Conhecimento Pedagógico de Conteúdo (PCK), é o foco deste artigo. Mesmo com a longevidade do tema PCK, as bases teóricas e metodológicas usadas nestas investigações são dispersas, não há consenso quanto a conceitos, terminologia, abrangência e componentes dos modelos adotados para estudo do conhecimento de professores. Com o objetivo de identificar as diferentes visões sobre o conhecimento de professores de Física, presentes nos modelos apoiados na base teórica do PCK e adotados na condução de pesquisas em Ensino de Física, foi conduzida uma revisão sistemática da literatura para identificação dos modelos nelas adotados. Após a identificação destes, fez-se um estudo aprofundado das referências originais de cada modelo, para então proceder-se a análise comparativa com intuito de identificar suas similaridades, divergências e lacunas. Esta análise aponta que, em sua maioria, os modelos adotados para estudo do conhecimento de professores de Física, contemplam, para ca-

\footnotetext{
${ }^{+}$A comparative analysis of models used in the study of Physics teacher's Pedagogical Content Knowledge (PCK) in Brazil

* Recebido: agosto de 2019. Aceito: fevereiro de 2020.

${ }^{1}$ E-mails: stela.lima@cba.ifmt.edu.br; marponda@uol.com.br; geison.mello@cba.ifmt.edu.br
} 
racterização da base de conhecimento de professores, os mesmos Componentes. Porém, há divergências conceituais sobre a formação e desenvolvimento destes conhecimentos, assim como diferem as delimitações da abrangência de cada modelo. Percebe-se também, pela evolução temporal dos modelos adotados, que há uma tendência à especialização na modelagem dos conhecimentos de professores de Física.

Palavras-chave: Conhecimento de Professores; PCK; PTSK; Ensino de Física.

\begin{abstract}
The knowledge base of teachers has been the object of research in several areas of education, with different theoretical approaches, over many decades. Renowned authors in the field include Lee Shulman who introduced the concept of Pedagogical Content Knowledge (PCK) to the academic debate in the 1980s. Despite the longevity of the PCK theme, the theoretical and methodological bases used in these investigations are scattered, there is no agreement regarding the concepts, terminology and components of the models adopted to study teachers' knowledge. In order to identify the different visions about the knowledge of physics teachers in the models, based on PCK, adopted in conducting research in Physics Teaching, a systematic review of the literature was conducted. After the identification of these, the original references of each model were studied, for which a comparative analysis was carried out to identify their similarities, divergences and gaps. This analysis indicates that mostly of the models contemplate the same components for characterization of the knowledge base of teachers. However, there are conceptual differences about the formation and development of this knowledge, as well as the delimitations of the comprehensiveness of each model. It is also noticed, by the temporal evolution of the adopted models, that there is a tendency to specialize in the modeling of the knowledge of Physics teachers.
\end{abstract}

Keywords: Teacher Knowledge; PCK; PTSK; Physics Teaching. 


\section{Introdução}

A busca pela valorização e reconhecimento da identidade profissional docente é uma constante ao longo das últimas décadas. A distinção do professor como categoria profissional implica na "necessidade de definir a especificidade da formação profissional docente" (NÓVOA, 2017, p. 1114). Para tanto, dentre as várias dimensões que compõem a formação de professores, a identificação da base de conhecimento, científicos e pedagógicos, que fazem do professor um especialista em ensinar é fundamental (SHULMAN, 2005).

Nesta perspectiva, ao longo das décadas diferentes autores propuseram distintas abordagens teóricas para compreensão desta base de conhecimentos (SHULMAN, 1986; 1987; GAUTIER, 1998; TARDIF, 2010), dentre as quais observa-se nas pesquisas de Lee Shulman um ponto de inflexão, com a configuração do modelo do Conhecimento Pedagógico do Conteúdo ( $\mathrm{PCK}^{2}$ ), na década de 80 (VIEIRA; MELO; BERNARDO, 2014). Sua proposta aborda, além dos Conhecimentos Disciplinares e Pedagógicos Gerais, o Conhecimento Pedagógico do Conteúdo (PCK) como um Componente necessário para formação da base de conhecimento de professores. Assim, o PCK consiste naquele conhecimento que é exclusivo do professor, o "amálgama especial de conteúdo e pedagogia" (SHULMAN, 1987, p. 8), que permite ao professor 'pegadogizar' o conteúdo de modo a torná-lo compreensível ao aluno.

Ao longo de seus mais de 30 anos de vida, o modelo PCK passou por várias análises e sugestões de adaptações pela comunidade científica, de maneira que mais de 18 modelos derivados no PCK foram propostos neste período (GOES, 2014³). Os diversos constructos propostos têm como ponto comum seu potencial em contribuir no delineamento de uma formação docente que abranja a complexa rede de conhecimentos necessária ao professor (FERNANDEZ, 2011). Esta ampla gama de modelos, embora traga novos olhares sobre o tema, também gera falta de unicidade quanto a conceitos e terminologias, assim como dificulta o desenvolvimento de metodologias avaliativas que sejam reconhecidas por toda comunidade acadêmica (BERRY; FRIEDRICHSEN; LOUGHRAN, 2015).

Apesar de grande parte dos modelos propostos reconhecerem o papel proeminente do conteúdo a ser ensinado na construção da base de conhecimento de professores (SHULMAN, 2005; GESS-NEWSOME; CARLSON, 2013a), poucos são os modelos focados em uma área de conhecimento específica, ou seja, que estabelecem a relação do conteúdo como um condicionante da pedagogia.

No entanto, percebe-se que "em trabalhos recentes a visão de Shulman de atrelar conteúdo à didática vem sendo consolidada" (FERNANDEZ, 2011, p. 3). Fato este que pode ser observado na proposição de modelos de caráter especializados no conhecimento de professores de disciplinas específicas, tais como os propostos por Ball, Thames e Phelps (2008),

\footnotetext{
2 Sigla em inglês para: Pedagogical Content Knowledge.

3 Pesquisa de mestrado que analisou 3.329 publicações nacionais e internacionais que abordassem o Conhecimento Pedagógico do Conteúdo (PCK) no período de 1986 a 2013.
} 
Carrillo et al. (2014), Luís, Monteiro e Carrillo (2015) e Soares (2019).

Aliado a este movimento em prol da especialização na identificação da base de conhecimento de professores em cada área disciplinar, há também a busca por alinhamento conceitual e metodológico na comunidade internacional. No ano de 2012 foi realizada a primeira Cúpula do PCK, que reuniu pesquisadores de renome das áreas de Ciências e Matemática ${ }^{4}$, com o intuito de obter alinhamento internacional nas pesquisas sobre o conhecimento de professores. Como fruto desta reunião foi proposto o modelo do PCK da Cúpula, (GESSNEWSOME; CARLSON, 2013b), que por sua vez foi revisado na $2^{\mathrm{a}}$ edição do congresso em 2016 e originou o Modelo Consensual Refinado do PCK (CHAN; ROLLNICK; GESSNEWSOME, 2019).

Frente ao contexto internacional, de alinhamento conceitual e especialização na descrição da base de conhecimento de professores de cada área disciplinar, justifica-se o interesse em identificar qual base teórica vem sendo utilizada, no Brasil, em pesquisas sobre a base de conhecimento de professores de Física sobe a perspectiva teórica proposta por Shulman (1986; 1987).

Assim o presente estudo tem por objetivo identificar as diferentes visões sobre o conhecimento de professores de Física presentes nos modelos apoiados na base teórica do PCK e adotados na condução de pesquisas em Ensino de Física durante o século XXI no Brasil. São objetivos específicos:

1. Identificar os modelos de conhecimento de professores usados nas pesquisas em Ensino de Física no Brasil nos primeiros 18 anos do século XXI;

2. Caracterizar a abordagem teórica dos modelos identificados; e

3. Observar pontos de convergência, divergências e lacunas entre estes modelos.

\section{Percurso metodológico}

A presente pesquisa baseou-se na conjugação de metodologias de cunho documental, em um primeiro momento realizou-se uma revisão sistemática da literatura (MORANDI; CAMARGO, 2015), de modo a identificar os modelos, apoiados na base teórica do PCK, adotados para estudo do conhecimento de professores de Física. Após este levantamento, para aprofundar a compreensão dos modelos identificados, procedeu-se a uma revisão bibliográfica direcionada nas obras originais que os caracterizam. Como etapa final do trabalho, fez-se a análise comparativa entre os modelos pontuando suas convergências, divergências e lacunas.

\footnotetext{
${ }^{4}$ Grupos representados na Cúpula do PCK em 2012: Berry, Loughran e Cooper; Daehler e Heller; Kind; Fischer e Borowski; Gess-Newsome, Carlson e Gardner; Padila e Garritz; Park e Suh; Scheneider; Rollnick; VanDriel, Henze e Janassen; Friedrichesen, Lannin e Sickel; Smith e Banilower.
} 


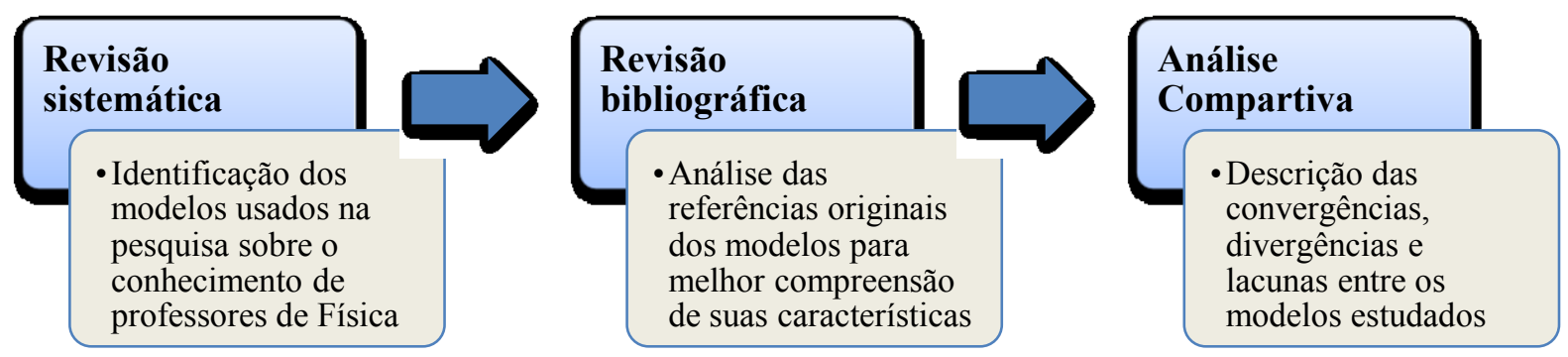

Fig. 1-Percurso metodológico. Fonte: Produção dos autores.

A Revisão Sistemática da Literatura é uma metodologia para mapear, consolidar e agregar resultados de diversos estudos, com o intuído de gerar conhecimento (MORANDI; CAMARGO, 2015). Desta forma, a questão central da revisão sistemática desta pesquisa pode ser traduzida em: quais são os modelos, apoiados na base teórica do PCK, usados para estudar os conhecimentos de professores de Física, ao longo dos primeiros 18 anos do século XXI, no âmbito acadêmico brasileiro?

Para condução da revisão sistemática foram selecionados periódicos qualificados na CAPES, com Qualis igual ou superior a B3, da área de educação e/ou ensino cujo título contivesse os termos "Física" ou "Ciências". Neste ponto da busca verificou-se a existência de periódicos não nacionais que atendiam a estes critérios na plataforma Sucupira ${ }^{5}$, este fato deve-se aos descritores usados "Física" ou "Ciências" serem cognatos nos idiomas português, espanhol e italiano.

Uma vez que o objetivo da pesquisa era identificar as diferentes visões sobre o conhecimento de professores de Física presentes nos modelos apoiados na base teórica do PCK e adotados na condução de pesquisas em Ensino de Física durante o século XXI no Brasil, optou-se pela manutenção destes periódicos na base de busca da revisão sistemática, pelo entendimento que, uma vez que as publicações são qualificadas pela CAPES, seus textos estão facilmente disponíveis para comunidade acadêmica brasileira, de modo que, mesmo não abordando pesquisas conduzidas especificamente no Brasil, compõem o conhecimento acadêmico nacional sobre o tema e serão identificadas em buscas feitas por pesquisadores brasileiros na língua portuguesa na plataforma Sucupira com os descritores "Física" ou "Ciências", tal como ocorrido na busca ora relatada.

Depois de selecionados os periódicos o processo de busca se deu pelo uso de descritores tais como: "conhecimento profissional", "conhecimento(s) docente(s)", "conhecimento(s) de/do(s) professor(es)", "conhecimento de/do docente(s)" e a conjugação de termos que compunham estes descritores como por exemplo "conhecimento" AND/+ "docente". No caso de periódicos com baixo índice de retorno chegou-se a pesquisar apenas o descritor "conhe-

\footnotetext{
${ }^{5}$ Link da plataforma Sucupira:

$<$ https://sucupira.capes.gov.br/sucupira/public/consultas/coleta/veiculoPublicacaoQualis/listaConsultaGeralPerio dicos.jsf $>$.
} 
cimento". A janela temporal considerada nas buscas foi de 2001 a 2018, ou seja, os anos já concluídos do século XXI. O mesmo processo de busca foi realizado no Catálogo de Teses e Dissertações CAPES.

Dentro do universo de publicações levantado, conduziu-se uma avaliação para identificação daqueles potencialmente relevantes ao tema da presente revisão sistemática. Esta seleção deu-se por leitura inspecional dos títulos e resumos, na qual se verificou seu alinhamento com a questão da revisão. Na sequência, procedeu-se a leitura analítica, na qual os estudos foram avaliados com base em três dimensões, sendo elas: (i) Qualidade da execução; (ii) Adequação à questão de revisão; e (iii) Adequação ao foco da revisão. Cada estudo foi classificado quanto ao atendimento de cada uma das dimensões como: Alta; Média ou Baixa (MORANDI; CAMARGO, 2015). Os critérios adotados para esta classificação estão descritos no Quadro .

Quadro 1 - Classificação das dimensões dos estudos.

\begin{tabular}{|c|c|c|c|}
\hline \multirow{2}{*}{ Classificação } & \multicolumn{3}{|c|}{ Dimensão } \\
\cline { 2 - 4 } Alta & Qualidade da execução & Adequação à questão da revisão & Adequação ao foco da revisão \\
\hline$(3)$ & $\begin{array}{c}\text { Tem por foco a análise } \\
\text { de conteúdos específi- } \\
\text { cos da Física. }\end{array}$ & $\begin{array}{c}\text { Adota um modelo específico } \\
\text { para estudo do conhecimento de } \\
\text { professores de Física. }\end{array}$ & $\begin{array}{c}\text { Envolve o estudo de conheci- } \\
\text { mento de professores de Física } \\
\text { no Brasil. }\end{array}$ \\
\hline $\begin{array}{c}\text { Média } \\
(2)\end{array}$ & $\begin{array}{c}\text { Tem por foco a análise } \\
\text { genérica da Física. }\end{array}$ & $\begin{array}{c}\text { Adota um modelo para estudo } \\
\text { do conhecimento de professo- } \\
\text { res. }\end{array}$ & $\begin{array}{c}\text { Envolve o estudo de conheci- } \\
\text { mento de professores de Física } \\
\text { fora do Brasil. }\end{array}$ \\
\hline $\begin{array}{c}\text { Baixa } \\
(1)\end{array}$ & $\begin{array}{c}\text { O estudo não tem foco } \\
\text { na Física. }\end{array}$ & $\begin{array}{c}\text { Não adota modelo para estudo } \\
\text { do conhecimento de professo- } \\
\text { res. }\end{array}$ & $\begin{array}{c}\text { Não envolve o estudo de co- } \\
\text { nhecimento de professores de } \\
\text { Física }\end{array}$ \\
\hline
\end{tabular}

Fonte: Adaptado de Harden e Gough (2012) apud Morandi e Camargo (2015).

Após a classificação de cada estudo em cada uma das três dimensões, as avaliações foram consolidadas conforme os parâmetros descritos no Quadro . Nesta revisão sistemática foram considerados para prosseguimento da análise apenas aqueles com pós-avaliação "Alta".

Quadro 2 - Parâmetros para pré-avaliação do estudo em função da avaliação de suas dimensões.

\begin{tabular}{|c|c|c|c|}
\hline \multicolumn{3}{|c|}{ Avaliação das dimensões } & \multirow[b]{2}{*}{$\begin{array}{l}\text { Pós-avaliação } \\
\text { do estudo }\end{array}$} \\
\hline $\begin{array}{l}\text { Qualidade da execução } \\
\text { Peso da dimensão }=2\end{array}$ & $\begin{array}{c}\text { Adequação à questão da revi- } \\
\text { são } \\
\text { Peso da dimensão }=3\end{array}$ & $\begin{array}{c}\text { Adequação ao foco da revi- } \\
\text { são } \\
\text { Peso da dimensão }=1\end{array}$ & \\
\hline Alta $=6$ & Alta $=9$ & Alta $=3$ & Alta $>12$ \\
\hline Média $=4$ & Média $=6$ & Média $=2$ & $12 \geq$ Média $>6$ \\
\hline Baixa $=2$ & Baixa $=3$ & Baixa $=1$ & Baixa $\leq 6$ \\
\hline
\end{tabular}

Fonte: Adaptado de Harden e Gough (2012) apud MORANDI e CAMARGO (2015). 
O sistema de pesos adotado para classificação das dimensões teve como balizador a escassez de estudos identificados. Desta forma priorizou-se, com peso 3, a adequação à questão da revisão, garantindo-se, assim, que pesquisas que adotassem um modelo, apoiado na base teórica do PCK, para investigação do conhecimento de professores de Física só não fossem incluídos se apresentassem baixa qualidade de execução e baixa adequação ao foco da revisão.

Identificados os estudos, os modelos foram estudados a partir da obra dos autores originais que o propuseram e a caracterização destes feita, de modo sucinto, no texto do artigo. Com base nas leituras feitas das obras originais e de outros autores de referência na área de pesquisa do PCK foram comparadas as principais características dos modelos, tais como seus componentes e a compreensão de cada autor sobre o processo de formação e desenvolvimento da base de conhecimento de professores.

\section{Resultados}

Os resultados da revisão sistemática que são apresentados a seguir iniciam-se pela identificação e caracterização dos modelos abordados nas pesquisas sobre o conhecimento de professores de Física. Com base nestas informações, apresenta-se a análise comparativa entre os modelos usados como ferramenta metodológica nas pesquisas sobre o conhecimento de professores de Física.

\section{III.1 Modelos usados nas pesquisas sobre o conhecimento de professores de Física}

Após busca na plataforma Sucupira para seleção dos periódicos identificou-se que atendiam aos critérios estabelecidos 13 periódicos, sendo 3 em espanhol, 1 em italiano e 9 em português. As buscas nos periódicos resultaram, após a exclusão de repetições, na identificação de 272 estudos que atendiam a janela temporal e aos descritores adotados. No Catálogo de Teses e Dissertações da CAPES foram identificados 35 trabalhos. Dentre os 307 estudos, 32 foram pré-selecionados após a leitura inspecional dos títulos e resumos, a quantidade de publicações identificadas e pré-selecionados encontra-se detalhada na Tabela .

Tabela 1 - Quantidade de estudos identificados, pré e pós-selecionados por periódico.

\begin{tabular}{cccc}
\hline \multirow{2}{*}{ Periódico } & \multicolumn{3}{c}{ Quantidade de estudos } \\
\cline { 2 - 4 } & Identificados & Pré-selecionados & Pós-selecionados \\
\hline A Física na Escola & - & - & - \\
Caderno Brasileiro de Ensino de Física & 62 & 10 & 2 \\
Caderno de Física da UEFS & 57 & 0 & - \\
Ciência \& Educação & 35 & 2 & - \\
Ciência \& Ensino & 2 & - & - \\
Ciência e Desenvolvimento - Revista & 4 & - & - \\
\hline
\end{tabular}




\begin{tabular}{cccc}
\hline Eletrônica da FAINOR (BA) & & - & - \\
E-Boletim da Física & - & 2 & 1 \\
Ensaio. Pesquisa em Educação em Ciências & 10 & 3 & 1 \\
Enseñanza de las Ciencias & 24 & - & - \\
Física y Cultura: Cuadernos Sobre Historia & - & - & - \\
y Enseñanza de las Ciencias & & 2 & 2 \\
La Fisica nella Scuola & 4 & 5 & 3 \\
Revista Brasileira de Ensino de Física & 26 & 7 & - \\
Revista de Enseñanza de la Física & 48 & 35 &
\end{tabular}

Fonte: Produção dos autores

A leitura analítica dos 32 estudos pré-selecionados resultou na avaliação destes em cada dimensão, conforme Quadro 1, tendo-se que 11 atendiam ao critério de pós-avaliação estabelecido, nota superior a 12, sendo estes destacados no Quadro 1 e sua quantificação por base de dados detalhada na última coluna da Tabela .

Quadro 1 - Resultado das avaliações das dimensões dos estudos.

\begin{tabular}{|c|c|c|c|c|c|c|}
\hline \multirow[b]{2}{*}{ Autores (Ano) } & \multirow[b]{2}{*}{ Tipo } & \multirow[b]{2}{*}{ Idioma } & \multicolumn{3}{|c|}{ Pré-avaliação } & \multirow[b]{2}{*}{$\begin{array}{c}\text { Pós- } \\
\text { avalia- } \\
\text { ção }\end{array}$} \\
\hline & & & $\begin{array}{c}\text { Quali- } \\
\text { dade }\end{array}$ & $\begin{array}{c}\text { Questão } \\
\text { da revi- } \\
\text { são }\end{array}$ & $\begin{array}{c}\text { Foco } \\
d a \\
\text { revisão }\end{array}$ & \\
\hline Adúriz-Bravo (2017) & Artigo & Espanhol & Alta & Baixa & Média & Média \\
\hline Brines; Solaz e Sanjosé (2016) & Artigo & Espanhol & Alta & Alta & Média & Alta \\
\hline Cindra e Teixeira (2005) & Artigo & Português & Alta & Baixa & Alta & Média \\
\hline Clebsch (2018) & Tese & Português & Média & Baixa & Alta & Média \\
\hline Coelho; Nunes e Wiehe (2008) & Artigo & Português & Alta & Baixa & Baixa & Média \\
\hline Cordeiro e Peduzzi (2013) & Artigo & Português & Média & Baixa & Alta & Média \\
\hline Corrêa Filho e Pacca (2011) & Artigo & Português & Alta & Baixa & Alta & Média \\
\hline Cortes Junior e Sá (2017) & Artigo & Português & Alta & Alta & Alta & Alta \\
\hline Cunha (2013) & Tese & Português & Média & Baixa & Alta & Média \\
\hline Cunha (2017) & Dissertação & Português & Alta & Alta & Alta & Alta \\
\hline Favretto (2018) & Dissertação & Português & Alta & Alta & Alta & Alta \\
\hline Giménez et al. (2015) & Artigo & Espanhol & Alta & Baixa & Alta & Média \\
\hline Goes (2014) & Dissertação & Português & Baixa & Média & Média & Média \\
\hline Justi et al. (2011) & Artigo & Espanhol & Baixa & Média & Baixa & Média \\
\hline Lescano; Sánchez e Lorenzo (2018) & Artigo & Espanhol & Alta & Alta & Média & Alta \\
\hline Lima (2018) & Dissertação & Português & Alta & Alta & Alta & Alta \\
\hline Marcelo; Yot e Perera (2016) & Artigo & Espanhol & Média & Baixa & Média & Média \\
\hline Martins (2008) & Artigo & Português & Média & Baixa & Alta & Média \\
\hline Melo e Cañada (2018) & Artigo & Espanhol & Alta & Alta & Média & Alta \\
\hline
\end{tabular}




\begin{tabular}{|c|c|c|c|c|c|c|}
\hline Melo; Cañada e Díaz (2017) & Artigo & Espanhol & Alta & Alta & Média & Alta \\
\hline Pena (2012) & Artigo & Português & Média & Baixa & Alta & Média \\
\hline Piratelo; Passos e Arruda (2014) & Artigo & Português & Média & Baixa & Alta & Média \\
\hline Rocha; Roa e Stoessel (2017) & Artigo & Espanhol & Alta & Alta & Média & Alta \\
\hline Romanowski e Silva (2018) & Artigo & Português & Média & Baixa & Alta & Média \\
\hline Roncancio (2010) & Artigo & Espanhol & Alta & Baixa & Média & Média \\
\hline Santos e Curi (2012) & Artigo & Português & Média & Baixa & Alta & Média \\
\hline Schein e Coelho (2008) & Artigo & Português & Alta & Baixa & Baixa & Média \\
\hline Silva (2017) & Tese & Português & Média & Alta & Alta & Alta \\
\hline Silva e Martins (2018) & Artigo & Português & Média & Alta & Alta & Alta \\
\hline Silva; Sales e Alves (2018) & Artigo & Espanhol & Média & Baixa & Alta & Média \\
\hline Vieira; Melo e Bernardo (2014) & Artigo & Português & Média & Baixa & Alta & Média \\
\hline Zimermann e Bertani (2003) & Artigo & Português & Alta & Baixa & Baixa & Média \\
\hline
\end{tabular}

Fonte: Produção dos autores.

As avaliações das dimensões dos estudos (Quadro 3) basearam-se na leitura analítica dos textos. Assim, evitaram-se conclusões errôneas sobre sua classificação. Um exemplo desta análise meticulosa é o trabalho de Brines, Solaz e Sanjosé (2016), que tem como tema as pilhas galvânicas em atividade interdisciplinar de ensino de Ciências com docentes de Física e Química. Apesar da interdisciplinaridade presente, há no texto clareza quanto aos conteúdos específicos da Física abordados, tais como, correte elétrica e força eletromotriz. Desta forma a classificação do estudo foi "Alta" para as três dimensões analisadas.

Os trabalhos pós-selecionados de Silva (2017) e Silva e Martins (2018) contemplam a mesma pesquisa, sendo o primeiro a Tese e o segundo o artigo sobre os resultados da Tese desenvolvida, desta forma optou-se por conduzir as análises considerando-se apenas o artigo (SILVA; MARTINS, 2018), por ser este o meio de divulgação de maior impacto. Assim, passam a serem considerados apenas 10 estudos pós-selecionados.

Apesar de observar-se a existência de trabalhos pré-selecionados ao longo dos anos, percebe-se maior concentração nos últimos 3 anos, de 2016 a 2018. Já os pós-selecionados concentram-se apenas nestes anos, sendo um de 2016, quatro de 2017 e cinco de 2018, de forma que a comunidade acadêmica tem demonstrado interesse no debate iniciado por Lee Shulman na década de 80 do século passado.

Dentre os 10 estudos pós-selecionados há a adoção de 6 diferentes modelos, apoiados na base teórica do PCK, para condução da pesquisa acerca do conhecimento de professores de Física. Destes 5 adotam o PCK de Shulman (1986), outros 3 adotaram modelos derivados do PCK e 2 apresentaram novas propostas de modelagem dos conhecimentos de professores de Física, o detalhamento dos modelos adotados está no Quadro, percebe-se que 50\% dos trabalhos adotam o modelo proposto por Shulman (1986; 1987). 
Quadro 4 - Relação dos modelos adotados em cada estudo selecionado.

\begin{tabular}{cc}
\hline \multicolumn{1}{c}{ Modelos da Literatura } & \\
\hline Brines; Solaz e Sanjosé (2016) & \\
Cunha (2017) & PCK (1986; 1987) \\
Rocha; Roa e Stoessel (2017) & \\
Melo e Cañada (2018) & \\
Lescano; Sánchez e Lorenzo (2018) & Magnusson, Krajcik e \\
Melo; Cañada e Díaz (2017) & Borko (1999) \\
Cortes Junior e Sa (2017) & PCK da Cúpula (2013) \\
Favretto (2018) & Rollnick et al. (2008) \\
\hline Modelos Propostos & PCK/NdC (2018) \\
\hline Silva e Martins (2018) & PTSK (2018) \\
\hline
\end{tabular}

Fonte: Produção dos autores.

\section{III.2 Caracterização dos modelos identificados nas pesquisas}

A descrição das características centrais dos seis modelos identificados na revisão sistemática é feita a seguir, de modo sucinto e sem o uso de imagens, para que seja mantida a ênfase na análise comparativa entre os modelos.

\section{III.2.1 Modelo de Lee Shulman}

$\mathrm{Na}$ década de 80, Lee Shulman introduziu no debate acadêmico o conceito de Conhecimento Pedagógico do Conteúdo (PCK). Esta ideia ganhou força entre os pesquisadores e nos dias atuais, nem sempre, o uso do termo PCK se refere às ideias originais do autor que foram propostas em suas publicações de 1986 e 1987. Apresenta-se a seguir o constructo proposto por Shulman para representar a base de conhecimento de professores.

O modelo teórico proposto por Shulman visa a expor categorias que representem a base de conhecimento necessária aos professores para ensinar de modo a tipificar estes conhecimentos. Os Componentes propostos por Shulman (1987) são: (i) Conhecimento do conteúdo; (ii) Conhecimento Pedagógico Geral; (iii) Conhecimento do Contexto Educativo; (iv) Conhecimento Pedagógico do Conteúdo (PCK); (v) Conhecimento Curricular; (vi) Conhecimento dos Aprendizes e suas Características; e (vii) Conhecimento dos Fins, Propósitos e Valores Educacionais e suas Bases Filosóficas e Históricas.

No modelo o Conhecimento do conteúdo refere-se à área disciplinar do docente, tal como a Biologia, a Física, a Biologia, a Química ou a Matemática, domínio no qual o professor deve ter uma compreensão que ultrapasse o mero conhecimento de conceitos, é necessário que o professor conheça a estrutura de sua área disciplinar. $\mathrm{O}$ docente deve compreender os 
fundamentos da base teórica da disciplina (estrutura subjetiva), bem como as formas de produção e legitimação de novos conhecimentos na área (estrutura sintática). O autor ressalta que "Em diferentes áreas de conhecimento, as formas de discutir a estrutura do conhecimento do conteúdo diferem." (SHULMAN, 1986, p. 9, tradução nossa), o que denota o caráter especializado deste conhecimento.

\section{III.2.2 Modelo de Magnusson, Krajcik e Borko}

O modelo de Magnusson, Krajcik e Borko (1999) apresenta uma vertente mais específica que se propõe modelar os conhecimentos de professores de Ciências, com elementos específicos desta área disciplinar. Os Componentes propostos pelos autores são: (i) Orientações para o ensino de Ciências; (ii) Conhecimento e Crenças sobre o currículo de Ciências; (iii) Conhecimento e Crenças sobre a Avaliação de Ciências; (iv) Conhecimento e Crenças sobre o entendimento dos estudantes de tópicos específicos de Ciências; e (v) Conhecimento e Crenças sobre estratégias instrucionais para ensinar Ciências (MAGNUSSON; KRAJCIK; BORKO, 1999).

Neste modelo são apresentadas nove orientações para o ensino de Ciências que, segundo os autores, são moldadas por propósitos educacionais, o que justifica a inserção das crenças dos professores no modelo. Nestas orientações estão inclusos aspectos do conhecimento do conteúdo de Ciências, da Pedagogia Geral, do Contexto e dos Propósitos do Ensino de Ciências. As orientações apresentadas pelos autores são: (i) Processo; (ii) Rigor acadêmico; (iii) Didática; (iv) Mudança conceitual; (v) Atividades dirigidas; (vi) Descoberta; (vii) Ciência baseada em projetos; (viii) Investigação; e (ix) Investigação dirigida.

\section{III.2.3 Modelo de Rollnick, Bennett, Rhemtula, Dharsey e Ndlovu}

$\mathrm{Na}$ modelagem dos conhecimentos dos professores proposta por Rollnick et al. (2008) o PCK é entendido como a somatória dos vários conhecimentos que o compõe, que uma vez mobilizados geram manifestações destes conhecimentos, sendo estas perceptíveis na atuação docente durante o processo de ensino-aprendizagem. Os autores apresentam os seguintes Componentes do PCK: (i) Conhecimento do Contexto; (ii) Conhecimento do Conteúdo Disciplinar; (iii) Conhecimento Pedagógico Geral; e (iv) Conhecimento dos Estudantes (ROLLNICK et al., 2008).

Sendo que estes "componentes do conhecimento do professor se integram para produzir o PCK" (ROLLNICK et al., 2008, p. 1380), ou seja, como o PCK é formado pela soma de seus componentes, o termo 'integrar' não se traduz como uma ideia de transformação, mas sim somatória para formação de um conjunto maior, ou seja, cada um destes componentes estaria inserido no PCK, pois, a soma das partes forma o todo no modelo de Rollnick et al. (2008).

Além dos componentes descritos também são apresentadas as manifestações do conhecimento do professor, que em seu modelo são as seguintes: (i) Saliência curricular; (ii) 
Avaliação; (iii) Representações do conteúdo; e (iv) Estratégias instrucionais de um conteúdo específico. Na visão dos autores, as manifestações são as janelas de oportunidades que os pesquisadores têm para identificar os conhecimentos dos professores.

\section{III.2.4 Modelo do Conhecimento Pedagógico do Conteúdo da Cúpula (PCK da Cúpula)}

Os pesquisadores reunidos na Cúpula do PCK, em 2012, propuseram um modelo de conhecimento de professores de Ciências. Neste modelo a base de conhecimento de professores de Ciência é dividida em dois grupos, a Base de conhecimento profissional de professores e o Conhecimento profissional específico do tópico. Desta forma faz-se uma distinção entre os conhecimentos relacionados à área disciplinar e aqueles relacionados a um tópico específico da disciplina ensinada. Mesmo abordando-os separadamente, o modelo sustenta que há constante interação entre estes dois grupos de conhecimentos (GESS-NEWSOME e CARLSON, 2013b). Para cada grupo de conhecimentos foram definidos Componentes, sendo eles:

- Base de conhecimento profissional de professores: (i) Conhecimento do conteúdo disciplinar; (ii) Conhecimento pedagógico; (iii) Conhecimento curricular; (iv) Conhecimento da Avaliação; e (v) Conhecimento dos estudantes.

- Conhecimento profissional específico do tópico: (i) Conhecimento da compreensão dos alunos; (ii) Conhecimento de estratégia instrucional e representações do conteúdo; e (iii) Conhecimento das práticas da Ciência.

No modelo proposto o Contexto, as Crenças e Orientações dos professores são apresentados como fatores potencialmente capazes de amplificar ou restringir a atuação docente no processo de ensino-aprendizagem, sendo considerados, pelos autores, como amplificadores e/ou filtros (GESS-NEWSOME; CARLSON, 2013b).

Este modelo abrange aspectos além da base de conhecimento docente ao relacionar os resultados de aprendizagem dos alunos com suas crenças, conhecimentos prévios e comportamento, fatores que, no entendimento do grupo, atuam como filtros e/ou amplificadores de seus próprios resultados (GESS-NEWSOME; CARLSON, 2013b).

O PCK da Cúpula contempla também a retroalimentação existente no processo de ensino-aprendizagem, ao representar em seu modelo que os resultados dos alunos influenciam futuras interações entre o docente e o estudante e o desenvolvimento de toda base de conhecimento de professores.

\section{III.2.5 Modelo transformativo-reflexivo de PCK/NdC}

O modelo proposto por Silva e Martins (2018) descreve os conhecimentos necessários ao professor de Física, ou Ciências, para ensinar o tópico Natureza da Ciência (NdC). Em função deste foco específico o modelo apresenta Componentes, em sua maioria, com foco nos conteúdos metacientíficos. Apenas os conhecimentos que formam, por sua transformação, o $\mathrm{PCK} / \mathrm{NdC}$ apresentam características gerais, são eles: (i) Conhecimento do Contexto; (ii) Co- 
nhecimento do Conteúdo; e (iii) Conhecimento Pedagógico (SILVA; MARTINS, 2018).

$\mathrm{O}$ modelo apresenta que o $\mathrm{PCK} / \mathrm{NdC}$ é moldado pelas Orientações para o ensino de conteúdos metacientíficos de cada professor, para então constituírem-se os conhecimentos necessários para o ensino da Natureza da Ciência, cujos Componentes são: (i) Conhecimento do currículo de Ciências para ensinar conteúdos metacientíficos; (ii) Conhecimento da avaliação de conteúdos metacientíficos; (iii) Conhecimento da compreensão de Ciência dos estudantes; e (iv) Conhecimento das estratégias instrucionais para o ensino de conteúdos metacientíficos.

Os autores também apresentam a Reflexão colaborativa como um processo de desenvolvimento do PCK/NdC dos professores e dos demais Componentes do modelo. Assim o modelo, além de buscar descrever os conhecimentos dos professores para ensino do tópico, também se propõe a apresentar o processo de desenvolvimento desta base de conhecimento.

\section{III.2.6 Modelo do Conhecimento Especializado de Professores de Física (PTSK ${ }^{6}$ )}

O PTSK tem por objetivo descrever o conhecimento especializado necessário ao professor para ensinar Física. Desta forma no modelo são abordados apenas conhecimentos relacionados à Física, não estando inclusos, por exemplo, estratégias pedagógicas gerais, mas apenas aquelas que tenham por objetivo específico o ensino de conteúdos de Física.

No modelo a base de conhecimento docente é divida em dois grandes grupos, cada qual com três Componentes. O primeiro, Conhecimento Didático do Conteúdo, abrange: (i) Conhecimento das características da aprendizagem de Física; (ii) Conhecimento do ensino de Física; e (iii) Conhecimento dos parâmetros da aprendizagem de Física. O segundo, Conhecimento da Física, compreende: (i) Conhecimento dos tópicos da Física; (ii) Conhecimento da Estrutura da Física; e (iii) Conhecimento da prática da Física.

Além dos conhecimentos também são abordadas no modelo as crenças dos professores sobre Física e sobre o ensino e aprendizagem de Física, que influenciam as ações dos professores em todos os Componentes do PTSK (LIMA, 2018).

\section{III.3 Análise comparativa dos modelos identificados na revisão sistemática}

Dentre os diversos modelos apresentados, há um ponto convergente, o conceito de Base de Conhecimento como sendo o conjunto de informações sistematizadas das quais o professor dispõe para atuar, de modo intencional, durante o processo de ensino-aprendizagem. Este conceito não se alterou desde o modelo de Shulman (1986), no entanto o conceito de PCK, não é entendido de modo linear nos seis modelos presentes nos estudos pósselecionados.

Em sua primeira apresentação, o Conhecimento Pedagógico do Conteúdo (PCK) foi definido como sendo o conhecimento que habilita o professor a transformar o conteúdo disci-

\footnotetext{
${ }^{6}$ Sigla em inglês para: Physics Teacher's Specialized Knowledge.
} 
plinar em conteúdo ensinável. Ou seja, o professor valendo-se do Conhecimento do Conteúdo e do Conhecimento Pedagógico Geral adapta o conteúdo de modo a torná-lo mais compreensível aos alunos (SHULMAN, 1986; 1987).

Percebe-se que no modelo proposto por Shulman $(1986 ; 1987)$ o PCK tem características transformativas, ou seja, ele não representa a mera união dos conhecimentos disciplinares e pedagógicos, mas sim uma alteração destes conhecimentos originais para o desenvolvimento do PCK, um novo conhecimento, que possui características específicas.

Dentre os seis modelos, apenas o modelo de Rollnick et al. (2008) diverge desta visão, pois entende que o PCK apresenta características integrativas (GOES, 2014), ou seja, o PCK origina-se da união dos conhecimentos de base. Desta forma, não há a transformação dos conhecimentos anteriores, portanto o PCK não representa um novo conhecimento e sim a somatória de conhecimentos prévios.

Esta distinção, no entendimento do PCK, é bem caracterizada na discussão sobre suas formas de desenvolvimento, feita modelo de Gess-Newsome (1999), que analisa dois extremos na concepção de PCK: (i) Modelo Integrativo, no qual o PCK é uma somatória dos conhecimentos de base; e (ii) Modelo Transformativo, no qual o PCK é um novo conhecimento que emerge da transformação dos conhecimentos de base (Fig. 2).

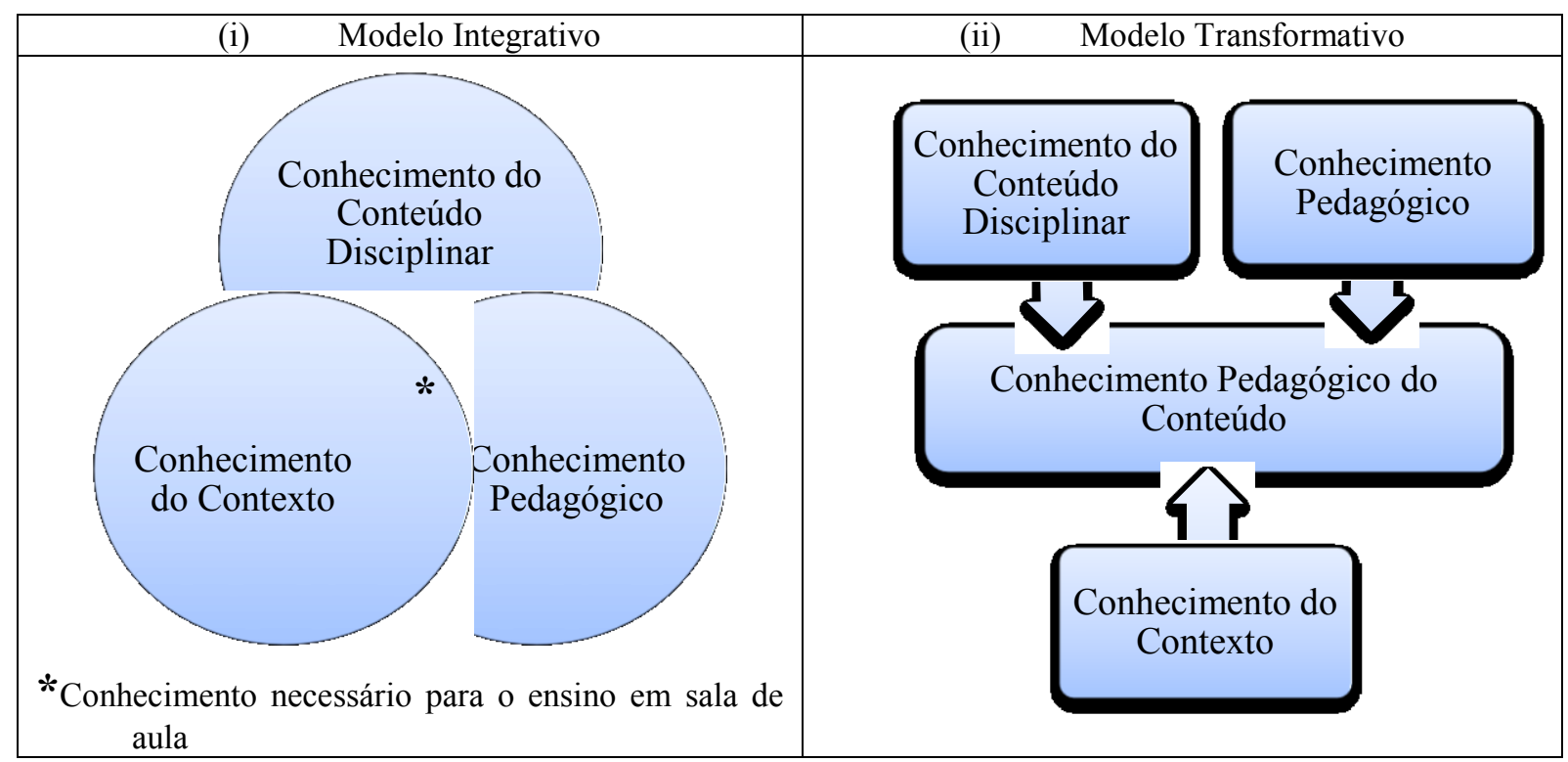

Fig. 2 - Modelo de desenvolvimento do PCK de Gess-Newsome (1999). Fonte: GESS-NEWSOME (1999, p. 12, tradução nossa).

A concepção do PCK, como um conhecimento integrativo ou transformativo, leva a adoção de distintos modelos de formação de professores. O entendimento que o PCK é fruto da somatória de conhecimentos distintos embasa a concepção de modelos formativos nos quais a apresentação dissociada dos diversos conhecimentos de base é adequada, pois o futuro 
professor desenvolverá seu PCK pela posterior integração destes conhecimentos (Modelo Integrativo, Fig. 2). Por outro lado, ao considerar o PCK como a transformação dos conhecimentos de base num novo conhecimento, faz-se necessária a adoção de modelos formativos que oportunizem ao futuro professor o desenvolvimento de seu PCK, pela apresentação interdisciplinar dos conhecimentos de base (Modelo Transformativo, Fig. 2).

Conforme analogia proposta por Testoni (2013) pode-se comparar o modelo integrativo a um fenômeno físico, no qual há interação entre as partículas, mas as estruturas originais são preservadas. Já o modelo transformativo assemelha-se a uma reação química, na qual após a ocorrência do fenômeno há mudança na estrutura original dos componentes formando-se uma nova substância.

Esta distinção na conceituação do PCK, como um novo conhecimento ou a somatória de conhecimentos, impacta também em como os Componentes do conhecimento de professores são abordados nos diversos modelos. Para Rollnick et al. (2008), como o PCK é formado pela acumulação dos distintos conhecimentos, todos os Componentes estão compreendidos no PCK. Para os demais autores, como o PCK é um conhecimento que emerge da transformação dos conhecimentos de base, há Componentes entendidos como conhecimentos da base pedagógica e conhecimentos da base disciplinar.

Além de abordar a base de conhecimento de professores, três modelos incluem suas crenças como fator que influencia o exercício da docência. O modelo de Magnusson, Krajcik e Borko (1999), relaciona-as apenas aos Componentes compreendidos no PCK dos professores, excluindo sua influência nos Conhecimentos da Base Profissional. Já nos modelos PTSK (LIMA, 2018) e PCK da Cúpula (GESS-NEWSOME; CARLSON, 2013b) as crenças dos professores, tanto a respeito da disciplina em si, quanto a respeito do processo de ensinoaprendizagem, permeiam as ações docentes (LIMA, 2018), atuando como fatores que as potencializam ou minoram (GESS-NEWSOME; CARLSON, 2013b).

Apesar de o modelo originalmente proposto por Shulman (1987) não incluir os aspectos subjetivos e pessoais de cada professor no exercício da docência, o autor considera atualmente que a inclusão destes fatores é adequada (SHULMAN, 2015). Os autores do modelo PCK/NdC (SILVA; MARTINS, 2018) e Rollnick et al. (2008) não incluem as crenças em suas propostas, nem como Componentes, nem como influenciadores.

Outra diferença conceitual identificada entre os modelos refere-se a sua abrangência, os dois modelos propostos em 2018, PTSK (LIMA, 2018) e PCK/NdC (SILVA; MARTINS, 2018), têm caráter especializado. O modelo PTSK tem como foco o conhecimento de professores de Física, assim todos seus Componentes têm por parâmetro primário a especialização do conhecimento. Aprofundando-se na especificidade do modelo, os autores do PCK/NdC visam a modelar os conhecimentos de professores para o ensino de um tópico, a Natureza da Ciência, fato ressaltado nos Componentes do modelo.

Esta busca, por um foco específico na modelagem dos conhecimentos de professores, pode ser observada também no modelo de Magnusson, Krajcik e Borko (1999), que abrange 
em sua proposta apenas os professores de Ciências, e no modelo proposto pela Cúpula do PCK (GESS-NEWSOME; CARLSON, 2013b), que, além de focar-se na área de Ciências, divide o conhecimento do professor em dois grupos, o primeiro, intitulado "Base de Conhecimento Profissional de Professores", com caráter mais generalista, e o segundo, o "Conhecimento Profissional Específico do Tópico", que caracteriza o conhecimento especializado de cada área disciplinar e compreende o PCK.

No tocante aos Componentes da base de conhecimento de professores adotado em cada modelo, há certa convergência quanto a seus focos centrais, apesar de divergências na nomenclatura adotada por cada autor. Identificou-se oito Componentes cujos focos centrais são o conhecimento sobre: (i) Contexto; (ii) Conteúdo Disciplinar; (iii) Pedagogia Geral; (iv) Currículo; (v) Avaliação; (vi) Estudantes e sua Aprendizagem; (vii) Pedagogia Específica; e (viii) Propósitos / Orientações.

Os Componentes de cada modelo foram organizados conforme seu foco central no Quadro 5, onde também se apresenta a classificação que cada autor confere ao Componente como compreendido no Conhecimento da Base Profissional ou no Conhecimento Pedagógico do Conteúdo. No Quadro 5 também há a identificação dos casos nos quais o Componente não é abordado pelo autor na apresentação do modelo.

Apenas três modelos não contemplam todos os oito Componentes. Shulman (1987) não aborda o conhecimento sobre Avaliações, aspecto já reconsiderado pelo próprio autor (SHULMAN, 2015). Na proposta de Rollnick et al. (2008) não são abordados os Propósitos Instrucionais, pois, apesar de haver menção as "Orientações específicas de conteúdo para o ensino", os autores referem-se à escolha de estratégias instrucionais e não aos Propósitos Educacionais, foco dado a este Componente nos demais modelos.

O Modelo PTSK não aborda dois dos Componentes identificados nos demais modelos: o conhecimento da Pedagogia Geral e o conhecimento do Contexto. O Contexto é compreendido por quatro modelos como um Componente da base de conhecimento de professores, porém no PTSK, apesar de ser considerado na metodologia de construção do modelo, o conhecimento do Contexto não consta da sua descrição final. Já no modelo da Cúpula do PCK (GESS-NEWSOME; CARLSON, 2013b) o Contexto não é considerado um Componente da base de conhecimento de professores, mas sim um amplificador, ou um filtro, para o processo de ensino-aprendizagem, que pode potencializar ou restringir as ações dos professores. No PCK da Cúpula há este mesmo entendimento a respeito dos Propósitos Educacionais (GESSNEWSOME; CARLSON, 2013b).

No tocante à não inclusão do conhecimento da Pedagogia Geral no PTSK, entende-se que esta seja uma consequência natural da proposta de especialização do modelo, pois são inclusos no PTSK apenas os conhecimentos didáticos associados ao processo de ensinoaprendizagem de Física (LIMA, 2018), ou seja, a Pedagogia Específica, que no modelo é denominada Conhecimento do Ensino de Física e inclui as Estratégias Instrucionais, Representações, Propósitos e a Avaliação, sempre relacionados a conteúdos de Física. Outros dois mo- 
delos relacionam o Componente do conhecimento da Pedagogia Específica ao tópico foco do processo de ensino-aprendizagem, o PCK/NdC (SILVA; MARTINS, 2018) e o PCK da Cúpula (GESS-NEWSOME; CARLSON, 2013b). Os demais modelos relacionam o conhecimento de estratégias instrucionais e representações ao conteúdo disciplinar de modo mais abrangente e não especificamente a um tópico da disciplina.

Ainda no Componente do conhecimento da Pedagogia Específica, há no PCK da Cúpula a presença de um aspecto diferenciado dos demais. $\mathrm{O}$ modelo inclui neste Componente o Conhecimento das Práticas da Ciência, ou seja, os modos de pensar e produzir em Ciências (GESS-NEWSOME; CARLSON, 2013b). Dois, dos outros cinco modelos, também abordam em sua descrição as formas de produção de conhecimentos na Ciência/Física, o modelo de Magnusson, Krajcik e Borko (1999) e o PTSK (LIMA, 2018), porém ambos o consideram compreendido no Conhecimento da Base Profissional relacionando-o ao conhecimento disciplinar.

A apresentação do conhecimento disciplinar em quatro dos seis modelos é feita de modo abrangente, sem subdivisões, sendo apresentado como Conhecimento do conteúdo. Ressalta-se que, apesar da ausência de subdivisões, em todos os modelos os autores são unânimes em enfatizar que o conhecimento do conteúdo, de modo fundamentado, é essencial na base de conhecimento de professores. Conforme coloca Shulman:

\footnotetext{
Os professores não devem ser capazes apenas de definir para os alunos as verdades aceitas em sua área de conhecimento. Eles também devem ser capazes de explicar por que uma determinada proposição é considerada justificada, por que vale a pena conhecê-la e como ela se relaciona com outras proposições, tanto na teoria quanto na prática (SHULMAN, 1986, p. 9, tradução nossa).
}

Apesar de não apresentar subdivisões para o conhecimento do conteúdo em seu modelo, Shulman entende que este abrange o conhecimento das estruturas substantivas e sintáticas da área específica, esta concepção alinha-se ao detalhamento do conhecimento do Conteúdo Disciplinar feito no PTSK, que o subdivide em três conhecimentos: Tópicos; Estrutura; e Prática (LIMA, 2018). O outro modelo que subdivide o conhecimento do conteúdo é o de Magnusson, Krajcik e Borko (1999), no entanto sua abordagem difere da feita por Shulman.

Magnusson, Krajcik e Borko (1999) abordam o conhecimento do conteúdo nos seguintes aspectos das orientações para o ensino de Ciências: Processo; Rigor acadêmico; $\mathrm{Mu}$ dança conceitual; e Investigação (MAGNUSSON; KRAJCIK; BORKO, 1999). As orientações, segundo os autores, são moldadas pelos Propósitos Educacionais, assim o conhecimento do conteúdo que se faz necessário para o ensino é influenciado pelos objetivos instrucionais estabelecidos.

As demais orientações presentes no modelo de Magnusson, Krajcik e Borko (1999) abordam conhecimentos dos Componentes Contexto e Pedagogia Geral, sendo esta última detalhada em: Didática; Atividades Dirigidas; Descoberta; Ciências baseada em projetos; e Investigação dirigida (MAGNUSSON; KRAJCIK; BORKO, 1999). Os demais modelos, com 
exceção do PTSK que não inclui a Pedagogia Geral, apresentam este Componente sem subdivisões.

O Componente Avaliação é considerado um conhecimento destacado das pedagogias, Geral e Específica, em cinco modelos apenas o PTSK o insere na Pedagogia Específica, incluindo-o no Conhecimento de Ensino de Física. Dois modelos focam o conhecimento da Avaliação em conteúdos específicos, o modelo de Magnusson, Krajcik e Borko (1999), Avaliação de Ciências, e o PCK/NdC, Avaliação de conteúdos metacientíficos. O PCK da Cúpula considera a Avaliação um Componente compreendido no Conhecimento da Base Profissional e, portanto, não focado em um tópico específico.

Os seis modelos abordam de modo similar o Componente Estudantes e sua Aprendizagem. Todos o consideram compreendido no Conhecimento Pedagógico do Conteúdo, porém no modelo PCK da Cúpula o conhecimento dos Estudantes e sua Aprendizagem é compreendido, também, no Conhecimento da Base Profissional (GESS-NEWSOME; CARLSON, 2013b). Os modelos que apresentam foco específico em áreas disciplinares (Ciências ou Física) ou conteúdos (Natureza da Ciência) apresentam esta delimitação também ao descreverem o conhecimento, como por exemplo, o PTSK que o descreve como Conhecimento das Características da Aprendizagem de Física (LIMA, 2018).

O último Componente a ser discutido, Currículo, é apresentado de modo equivalente em todos os modelos, havendo apenas maior delimitação de sua abrangência nos modelos de foco específico em disciplinas ou conteúdo. O Conhecimento Curricular é considerado como compreendido no Conhecimento da Base Profissional no modelo de Shulman (1987) e no PCK da Cúpula (GESS-NEWSOME; CARLSON, 2013b), para os demais autores ele está abarcado no Conhecimento Pedagógico do Conteúdo. Apesar desta distinção não há discrepâncias na apresentação deste Componente nos seis modelos identificados na revisão sistemática.

\section{Considerações finais}

A análise comparativa dos modelos, apoiados na base teórica do PCK, utilizados como ferramenta metodológica nas pesquisas sobre o conhecimento de professores de Física, permitiu a identificação das diferentes visões que embasam estas investigações no âmbito acadêmico nacional. Percebe-se que há pouca divergência no conceito de $\mathrm{PCK}$, prevalecendo a visão que ele é um conhecimento com características próprias, originado pela transformação dos Conhecimentos da Base Profissional.

A maioria dos autores considera adequada a inclusão de fatores subjetivos e pessoais, como as crenças dos professores, nos modelos de conhecimentos de professores. O mesmo ocorre com os Componentes da base de conhecimento de professores, tendo sido identificados oito focos centrais: (i) Conhecimento do Contexto; (ii) Conhecimento do Conteúdo Disciplinar; (iii) Conhecimento da Pedagogia Geral; (iv) Conhecimento do Currículo; (v) Conhecimento da Avaliação; (vi) Conhecimento dos Estudantes e sua Aprendizagem; (vii) Conheci- 
Quadro 5 - Síntese dos Componentes de conhecimentos de professores identificados em cada modelo por foco central.

\begin{tabular}{|c|c|c|c|c|c|c|c|c|}
\hline $\begin{array}{c}\text { Mode- } \\
\text { lo }\end{array}$ & Contexto & $\begin{array}{l}\text { Conteúdo } \\
\text { Disciplinar }\end{array}$ & $\begin{array}{l}\text { Peda- } \\
\text { gogia } \\
\text { Geral } \\
\end{array}$ & $\begin{array}{l}\text { Currí- } \\
\text { culo }\end{array}$ & $\begin{array}{l}\text { Avalia- } \\
\text { ção }\end{array}$ & $\begin{array}{c}\text { Estudantes e sua } \\
\text { Aprendizagem }\end{array}$ & $\begin{array}{l}\text { Pedagogia } \\
\text { Específica }\end{array}$ & $\begin{array}{c}\text { Propósitos } \\
\text { Educacio- } \\
\text { nais }\end{array}$ \\
\hline \multirow[t]{2}{*}{$\begin{array}{l}\text { Shul- } \\
\text { man } \\
(1987)\end{array}$} & $\begin{array}{l}\text { Conhe- } \\
\text { cimento } \\
\text { do Con- } \\
\text { texto } \\
\text { educativo }\end{array}$ & $\begin{array}{l}\text { Conhecimento } \\
\text { do Conteúdo }\end{array}$ & $\begin{array}{l}\text { Conhe- } \\
\text { cimento } \\
\text { pedagó- } \\
\text { gico } \\
\text { geral }\end{array}$ & $\begin{array}{l}\text { Conhe- } \\
\text { cimento } \\
\text { curricular }\end{array}$ & \multirow[t]{2}{*}{ NA } & $\begin{array}{c}\text { Conhecimento } \\
\text { dos aprendizes e } \\
\text { suas característi- } \\
\text { cas }\end{array}$ & $\begin{array}{l}\text { Conhecimento } \\
\text { pedagógico do } \\
\text { conteúdo }\end{array}$ & $\begin{array}{c}\text { Conh. dos } \\
\text { fins, propó- } \\
\text { sitos e } \\
\text { valores } \\
\text { educacio- } \\
\text { nais e suas } \\
\text { bases } \\
\text { filosóficas } \\
\text { e históricas } \\
\end{array}$ \\
\hline & CBP & CBP & CBP & CBP & & PCK & PCK & CBP \\
\hline \multirow[t]{2}{*}{$\begin{array}{l}\text { Mag- } \\
\text { nus- } \\
\text { son, } \\
\text { Kra- } \\
\text { jcik e } \\
\text { Borko } \\
\text { (1999) } \\
\end{array}$} & \multicolumn{3}{|c|}{$\begin{array}{l}\text { Abordados nas nove orientações para o } \\
\text { ensino de ciências (Processo; Rigor } \\
\text { acadêmico; Didática; Mudança concei- } \\
\text { tual; Atividades dirigidas; Descoberta; } \\
\text { Ciência baseada em projetos; Investi- } \\
\text { gação; e Investigação dirigida). }\end{array}$} & $\begin{array}{l}\text { Conh. e } \\
\text { crenças } \\
\text { sobre o } \\
\text { currículo } \\
\quad \text { de } \\
\text { Ciências }\end{array}$ & \begin{tabular}{|c|} 
Conh. e \\
crenças \\
sobre a \\
avalia- \\
ção de \\
Ciências
\end{tabular} & $\begin{array}{l}\text { Conh. e crenças } \\
\text { sobre o entendi- } \\
\text { mento dos estu- } \\
\text { dantes de tópicos } \\
\text { específicos de } \\
\text { Ciências }\end{array}$ & $\begin{array}{l}\text { Conh. e } \\
\text { crenças sobre } \\
\text { estratégias } \\
\text { instrucionais } \\
\text { para ensinar } \\
\text { Ciências }\end{array}$ & $\begin{array}{l}\text { Orienta- } \\
\text { ções para o } \\
\text { ensino de } \\
\text { Ciências }\end{array}$ \\
\hline & CBP & CBP & CBP & PCK & PCK & PCK & PCK & PCK \\
\hline \multirow[t]{2}{*}{$\begin{array}{l}\text { Rollni } \\
\text { ck } \\
\text { et al. } \\
(2008)\end{array}$} & $\begin{array}{l}\text { Conh. do } \\
\text { Contexto }\end{array}$ & $\begin{array}{l}\text { Conh. do conte- } \\
\text { údo disciplinar }\end{array}$ & $\begin{array}{l}\text { Conh. } \\
\text { pedagó- } \\
\text { gico } \\
\text { geral }\end{array}$ & $\begin{array}{l}\text { Saliência } \\
\text { curricular }\end{array}$ & $\begin{array}{l}\text { Avalia- } \\
\text { ção }\end{array}$ & $\begin{array}{l}\text { Conh. dos estu- } \\
\text { dantes }\end{array}$ & $\begin{array}{l}\text { Representações } \\
\text { do conteúdo; } \\
\text { Estratégias } \\
\text { instrucionais de } \\
\text { um conteúdo } \\
\text { específico; } \\
\end{array}$ & \multirow[t]{2}{*}{ NA } \\
\hline & PCK & PCK & PCK & PCK & PCK & PCK & PCK & \\
\hline \multirow{4}{*}{$\begin{array}{l}\text { PCK } \\
\text { da } \\
\text { Cúpu- } \\
\text { la } \\
(\mathbf{2 0 1 3})\end{array}$} & \multirow{4}{*}{$\begin{array}{l}\text { O Con- } \\
\text { texto é } \\
\text { um Filtro } \\
\text { / Amplifi- } \\
\text { cador }\end{array}$} & Base de Conh & ecimento & Drficiof & de Professo & Conh. Prof & îssional Específice & Tópico \\
\hline & & $\begin{array}{l}\text { Conh. do conte- } \\
\text { údo disciplinar }\end{array}$ & $\begin{array}{l}\text { Conh. } \\
\text { peda- } \\
\text { gógico }\end{array}$ & $\begin{array}{l}\text { Conh. } \\
\text { curricular }\end{array}$ & $\begin{array}{l}\text { Conh. da } \\
\text { Avalia- } \\
\text { ção }\end{array}$ & $\begin{array}{l}\text { Conh. dos estu- } \\
\text { dantes }\end{array}$ & \begin{tabular}{|c|} 
Conh. de estra- \\
tégia instrucio- \\
nal e represen- \\
tações do con- \\
teúdo; Conh. \\
das práticas da \\
Ciência \\
\end{tabular} & \multirow[t]{3}{*}{$\begin{array}{c}\text { As orien- } \\
\text { tações são } \\
\text { considera- } \\
\text { das um } \\
\text { Filtro / } \\
\text { Amplifi- } \\
\text { cador }\end{array}$} \\
\hline & & \multicolumn{6}{|c|}{ Filtro / Amplificador: Crença dos professores } & \\
\hline & & $\mathrm{CBP}$ & $\mathrm{CBP}$ & $\mathrm{CBP}$ & CBP & CBP / PCK & PCK & \\
\hline \multirow[t]{2}{*}{$\begin{array}{l}\text { PCK/ } \\
\text { NdC } \\
(\mathbf{2 0 1 8})\end{array}$} & $\begin{array}{l}\text { Conh. do } \\
\text { Contexto }\end{array}$ & $\begin{array}{l}\text { Conh. do conte- } \\
\text { údo }\end{array}$ & $\begin{array}{l}\text { Conh. } \\
\text { peda- } \\
\text { gógico }\end{array}$ & $\begin{array}{l}\text { Conh. do } \\
\text { currículo } \\
\text { de Ciêcias } \\
\text { para ensi- } \\
\text { nar conte- } \\
\text { údos meta- } \\
\text { científicos }\end{array}$ & \begin{tabular}{|c|} 
Conh. da \\
Avalia- \\
ção de \\
conteú- \\
dos \\
metaci- \\
entíficos
\end{tabular} & $\begin{array}{l}\text { Conh. da compre- } \\
\text { ensão de Ciência } \\
\text { dos estudantes }\end{array}$ & $\begin{array}{c}\text { Conh. das } \\
\text { estratégias } \\
\text { instrucionais } \\
\text { para o ensino } \\
\text { de conteúdos } \\
\text { metacientíficos }\end{array}$ & $\begin{array}{l}\text { Orienta- } \\
\text { ções para } \\
\text { o ensino } \\
\text { de conte- } \\
\text { údos } \\
\text { metacien- } \\
\text { tíficos }\end{array}$ \\
\hline & $\mathrm{CBP}$ & CBP & $\mathrm{BP}$ & PCK & PCK & PCK & PCK & PCK \\
\hline \multirow[t]{3}{*}{$\begin{array}{l}\text { PTSK } \\
\text { (2018) }\end{array}$} & \multirow[t]{3}{*}{ NA } & $\begin{array}{l}\text { Conh. dos tópi- } \\
\text { cos da Física; } \\
\text { Conh. da estru- } \\
\text { tura da Física; } \\
\text { Conh. da prática } \\
\text { da Física } \\
\end{array}$ & \multirow[t]{3}{*}{ NA } & $\begin{array}{l}\text { Conh. dos } \\
\text { parâmetros } \\
\text { da apren- } \\
\text { dizagem de } \\
\quad \text { Física }\end{array}$ & $\begin{array}{l}\text { Conh. } \\
\text { do ensi- } \\
\text { no de } \\
\text { Física }\end{array}$ & $\begin{array}{l}\text { Conh. das caracte- } \\
\text { rísticas da apren- } \\
\text { dizagem de Física }\end{array}$ & \multicolumn{2}{|c|}{ Conh. do ensino de Física } \\
\hline & & $\begin{array}{l}\text { Crenças sobre } \\
\text { Física }\end{array}$ & & \multicolumn{5}{|c|}{ Crenças sobre o Ensino e Aprendizagem de Física } \\
\hline & & $\mathrm{CBP}$ & & PCK & PCK & PCK & PCK & \\
\hline
\end{tabular}

$\mathrm{CBP}=$ Componente compreendido no Conhecimento da Base Profissional

PCK $=$ Componente compreendido no Conhecimento Pedagógico do Conteúdo

$\mathrm{NA}=$ Não abordado no modelo

Fonte: Adaptado e aprimorado a partir de Kind (2009) e Goes (2014) 
mento da Pedagogia Específica; e (viii) Conhecimento dos Propósitos / Orientações.

Há divergências de terminologias e nuances nas abordagens destes Componentes em cada modelo, porém são raros os casos em que todos estes oitos Componentes não são identificados, sendo estes: a não inclusão do Conhecimento da Avaliação no modelo de Shulman (1986; 1987); a ausência do Conhecimento dos Propósitos / Orientações na proposta de Rollnick et al. (2008); e no modelo PTSK (LIMA, 2018) não estão presentes o Conhecimento do Contexto e o Conhecimento da Pedagogia Geral.

A não inclusão do Conhecimento da Pedagogia Geral no PTSK deve-se a uma mudança de paradigma na modelagem proposta. O modelo abarca apenas os conhecimentos especializados de professores de Física. Esta tendência à especialização nos modelos utilizados nas pesquisas em ensino de Física foi notada também nos modelos propostos por Magnusson, Krajcik e Borko (1999), pela Cúpula do PCK (GESS-NEWSOME; CARLSON, 2013b) e por Silva e Martins (2018).

Esta tendência à especialização dos modelos na Física observada nos estudos da revisão sistemática segue um movimento similar ao ocorrido na matemática, na qual observa-se "um progresso, que vai do genérico ao especializado." (MORIEL JUNIOR; WIELEWSKI, 2017, p. 132). A concepção que os conhecimentos necessários ao professor, para o ensino de Física, são especializados favorece a profissionalização e valorização docente (MORIEL JUNIOR; WIELEWSKI, 2017), bem como auxilia na identificação sistemática destes conhecimentos e na elaboração de estratégias formativas, que por sua vez auxiliarão o docente a desenvolver sua base conhecimento, permitindo-lhe obter melhores resultados no aprendizado de seus alunos.

Lee Shulman relata que na época de sua primeira publicação "tratavam o ensino como um processo sem conteúdo, e os professores como atores habilidosos, sem mente, emoções e carreiras." (SHULMAN, 2015, p. 9). Apesar de, no âmbito acadêmico, terem ocorrido diversas evoluções na identificação da base de conhecimento de professores, não é possível afirmar que a visão dos idos anos 80, relatada por Shulman, foi alterada perante a sociedade e convertida em valorização profissional para os docentes.

A valorização profissional do docente passa pela identificação sistemática dos conhecimentos especializados dos professores de cada área de conhecimento, para que não haja retrocessos como a proposta de adoção do notório saber como atalho ao processo de formação para o ingresso no magistério.

\section{Referências}

ADÚRIZ-BRAVO, A. Pensar la enseñanza de la física en términos de "competencias". Revista de Enseñanza de la Física, n. 2, p. 21-31, dez. 2017.

BALL, D. L.; THAMES, M. H.; PHELPS, G. Content Knowledge for Teaching: What Makes It Special? Journal of teacher education, v. 59, n. 5, p. 389-407, 2008. 
BERRY, A.; FRIEDRICHSEN, P.; LOUGHRAN, J. Preface. In: BERRY, A.; FRIEDRICHSEN, P.; LOUGHRAN, J. (Ed.). Re-examining pedagogical content knowledge in science education: Routledge, 2015. p.ix - x. ISBN 1317564650.

BRINES, A. B.; SOLAZ, J. J.; SANJOSÉ, V. Estudio exploratorio comparativo del conocimiento didáctico del contenido sobre pilas galvánicas de profesores de secundaria en ejercicio y en formación. Enseñanza de las Ciencias: revista de investigación y experiencias didácticas, v. 34, n. 2, p. 0107-127, 2016. ISSN 2174-6486.

CARrillo, J. CLIMENT, N.; CONTRERAS, L. C.; MONTES, M. A.; ESCUDEROÁVILA, D.; FLORES-MEDRANO, E. Un marco teórico para el conocimiento especializado del professor de matemáticas. Universidad de Huelva Publicaciones, 2014.

CHAN, K. K. H.; ROLLNICK, M.; GESS-NEWSOME, J. A Grand Rubric for Measuring Science Teachers' Pedagogical Content Knowledge. In: (Ed.). Repositioning Pedagogical Content Knowledge in Teachers' Knowledge for Teaching Science: Springer, 2019. p.251-269.

CINDRA, J. L.; TEIXEIRA, O. P. B. A evolução das idéias relacionadas aos fenômenos térmicos e elétricos: Algumas similaridades. Caderno Brasileiro de Ensino de Física, v. 22, n. 3, p. 379-399, dez. 2005. ISSN 2175-7941.

CLEBSCH, A. B. Construção dos saberes docentes na formação do licenciando em Física. 2018. 420 pf. Tese (Doutorado em Educação Cientifica e Tecnológica) - Centro de Ciências Físicas e Matemáticas, Programa de Pós-Graduação em Educação Científica e Tecnológica, Universidade Federal de Santa Catarina, Florianópolis.

COELHO, S. M.; NUNES, A. D.; WIEHE, L. C. N. Formação continuada de professores numa visão construtivista: contextos didáticos, estratégias e formas de aprendizagem no ensino experimental de Física. Caderno Brasileiro de Ensino de Física, v. 25, n. 1, p. 7-34, abr. 2008. ISSN 2175-7941.

CORDEIRO, M. D.; PEDUZZI, L. O. Q. Consequências das descontextualizações em um livro didático: uma análise do tema radioatividade. Revista Brasileira de Ensino de Física, v. 35, p. 1-11, 2013. ISSN 1806-1117. 
CORRÊA FILHO, J. A.; PACCA, J. L. A. Relatos de aulas de ótica no Ensino Médio: o quê eles nos revelam sobre a atuação do professor? Caderno Brasileiro de Ensino de Física, v. 28, n. 2, p. 297-324, ago. 2011. ISSN 2175-7941.

CORTES JUNIOR, L. P.; SÁ, L. P. Conhecimento Pedagógico do Conteúdo no Contexto da Educação Ambiental: Uma Experiência com Mestrandos em Ensino de Ciências. Ensaio Pesquisa em Educação em Ciências, v. 19, 2017. ISSN 1983-2117.

CUNHA, A. M. Saberes experienciais e estágio investigativo na formação de professores de física. 2013. Tese (Doutorado em Educação) - Faculdade de Educação, Universidade de São Paulo, São Paulo.

CUNHA, L. D. S. O Conhecimento Pedagógico do Conteúdo de licenciandos em Física numa proposta realizada através da parceria universidade-escola. 2017. $110 \mathrm{f}$. Dissertação (Mestrado em Educação em Ciências). Programa de pós-graduação em Educação em Ciências, Universidade Federal de Itajubá, Itajubá, 2017.

FAVRETTO, T. F. Ciências nos Anos Iniciais: Uma Investigação das Manifestações do Conhecimento Pedagógico do Conteúdo Sobre o Conceito de Energia. 2018. 191 f. Dissertação (Mestrado em Educação Científica e Tecnológica). Centro de Ciências Físicas e Matemáticas, Programa de Pós-Graduação em Educação Científica e Tecnológica, Universidade Federal de Santa Catarina, Florianópolis, 2018.

FERNANDEZ, C. PCK-Conhecimento Pedagógico do Conteúdo: perspectivas e possibilidades para a formação de professores. Encontro Nacional de Pesquisa em Educação em Ciências, v. 8, p. 1-12, 2011.

GAUTHIER, C. Por uma teoria da pedagogia: pesquisas contemporâneas sobre o saber docente. Ijuí: Unijuí, 1998.

GESS-NEWSOME, J. Pedagogical content knowledge: An introduction and orientation. In: (Ed.). Examining pedagogical content knowledge: Springer, 1999. p. 3-17.

GESS-NEWSOME, J.; CARLSON, J. An international perspective on pedagogical content knowledge. The Association for Science Teacher Education Conference, Charleston, SC, 2013a.

GESS-NEWSOME, J.; CARLSON, J. The PCK summit consensus model and definition of pedagogical content knowledge. Symposium "Reports from the Pedagogical Content Knowledge (PCK) Summit”, ESERA Conference, 2013b. 
GIMÉNEZ, J.; LÓPEZ, J.; AMADOR-RODRÍGUEZ, R.; MEINARDI, E. Representaciones de las prácticas de laboratorio en profesores en ejercicio. Revista de Enseñanza de la Física, n. extra, p. 259-267, nov. 2015.

GOES, L. F. D. Conhecimento Pedagógico do Conteúdo: Estado da Arte no campo da Educação e no Ensino de Química. 2014. 155f. Dissertação (Mestrado) - Instituto de Física, Instituto de Química, Instituto de Biociências, Faculdade de Educação, Universidade de São Paulo, São Paulo.

HARDEM, A.; GOUGH, D. Quality and relevance appraisal. In: GOUGH, D.; OLIVER, S.; THOMAS, J. An introduction to systematic reviews. London: Sage, 2012. p. 153-178.

JUSTI, R.; CHAMIZO GERRERO, J. A.; GARCÍA FRANCO, A.; FIGUEIRÊDO, K. L. Experiencias de formación de profesores latinoamericanos de ciencias sobre modelos $\mathrm{y}$ modelaje. Enseñanza de las Ciencias. Revista de investigación y experiencias didácticas, v. 29, n. 3, p. 413-426, nov. 2011.

KIND, V. Pedagogical content knowledge in science education: perspectives and potential for progress. Studies in science education, v. 45, n. 2, p. 169-204. 2009. ISSN 0305-7267.

LESCANO, A. J.; SÁNCHEZ, G. H.; LORENZO, M. G. Desarrollo del conocimiento profesional docente sobre espectroscopía durante un proceso de investigación-acción. Revista de Enseñanza de la Física, v. 30, n. Extra, p. 127-134, Nov. 2018. ISSN 2451-6007.

LIMA, S. S. Conhecimento Especializado de Professores de Física: Uma proposta de Modelo Teórico. 2018. 144 f. Dissertação (Mestrado em Ensino) - Programa de Pósgraduação em Ensino, Instituto Federal de Educação, Ciências e Tecnologias do Estado de Mato Grosso, Cuiabá.

LUÍS, M.; MONTEIRO, R.; CARRILLO, J. Conhecimento Especializado do Professor para Ensinar Ciências. In: ENCONTRO NACIONAL DE EDUCAÇÃO EM CIÊNCIAS, 2015, Lisboa, Portugal. Anais... APEduC. p. 1-6.

MAGNUSSON, S.; KRAJCIK, J.; BORKO, H. Nature, sources, and development of pedagogical content knowledge for science teaching. In: (Ed.). Examining pedagogical content knowledge: Springer, 1999. p. 95-132. 
MARCELO, C.; YOT, C.; PERERA, V. H. El conocimiento tecnológico y tecnopedagógico en la enseñanza de las ciencias en la universidad. Un estudio descriptivo. Enseñanza de las ciencias: revista de investigación y experiencias didácticas, v. 34, n. 2, p. 67-86, 2016 2016. ISSN 2174-6486.

MARTINS, A. F. P. História e Filosofia da Ciência no ensino: Há muitas pedras nesse caminho. Caderno Brasileiro de Ensino de Física, v. 24, n. 1, p. 112-131, abr. 2008. ISSN 2175-7941.

MELO, L.; CAÑADA, F. Emociones que emergen durante el análisis del conocimiento didáctico del contenido sobre el campo eléctrico. Ciência \& Educação, v. 24, p. 57-70, 2018. ISSN 1516-7313.

MELO, L.; CAÑADA, F.; DÍAZ, M. Formación continua del profesorado de Física a través del conocimiento didáctico del contenido sobre el campo eléctrico en Bachillerato: un caso de estudio. Caderno Brasileiro de Ensino de Física, v. 34, n. 1, p. 131-151, 2017. ISSN 2175 7941.

MORANDI, M. I. W. M.; CAMARGO, L. F. R. Revisão sistemática da literatura. In: DRESCH, A.; LACERDA, D. P.; ANTUNES JÚNIOR, J. A. V. (Ed.). Design science research: método de pesquisa para avanço da ciência e tecnologia. Porto Alegre: Bookman, 2015. cap. 6, p.141-172.

MORIEL JUNIOR, J. G.; WIELEWSKI, G. D. Base de conhecimento de professores de matemática: do genérico ao especializado. Revista de Ensino, Educação e Ciências Humanas, v. 18, n. 2, p. 126-133, 2017. ISSN 2447-8733.

NÓVOA, A. Firmar a posição como professor, afirmar a profissão docente. Cadernos de Pesquisa, v. 47, n. 166, p. 1106-1133, dez. 2017. ISSN 0100-1574.

PENA, F. L. A. Sobre a presença do Projeto Harvard no sistema educacional brasileiro. Revista Brasileira de Ensino de Física, v. 34, p. 1-4, 2012. ISSN 1806-1117.

PIRATELO, M. V. M.; PASSOS, M. M.; ARRUDA, S. D. M. Um estudo a respeito das evidências de aprendizado docente no PIBID da Licenciatura em Física. Caderno Brasileiro de Ensino de Física, v. 31, n. 3, p. 493-517, dez. 2014. ISSN 2175-7941. 
ROCHA, A.; ROA, M.; STOESSEL, A. F. Estudios sobre el profesor. Análisis de un caso en la enseñanza universitaria en ingeniería. Revista de Enseñanza de la Física, n. extra, p. 129138, nov. 2017.

ROLLNICK, M.; BENNETT, J.; RHEMTULA, M.; DHARSEY, N.; NDLOVU, T. The place of subject matter knowledge in pedagogical content knowledge: A case study of South African teachers teaching the amount of substance and chemical equilibrium. International Journal of Science Education, v. 30, n. 10, p. 1365-1387, 2008. ISSN 0950-0693.

ROMANOWSKI, J. P.; SILVA, P. J. D. A Formação pedagógica no curso de licenciatura em física: articulação entre os campos do conhecimento. Ensaio Pesquisa em Educação em Ciências, v. 20, 2018. ISSN 1983-2117.

RONCANCIO, J. D. R. Tendencias en investigación en el Conocimiento Pedagógico de Contenido de profesores de física en formación inicial. Revista de Enseñanza de la Física, n. 1 e 2, p. 7-19, 2010.

SANTOS, C. A. B. D.; CURI, E. A formação dos professores que ensinam física no ensino médio. Ciência \& Educação, v. 18, p. 837-849, 2012. ISSN 1516-7313.

SCHEIN, Z. P.; COELHO, S. M. O papel do questionamento: intervenções do professor e do aluno na construção do conhecimento. Caderno Brasileiro de Ensino de Física, v. 23, n. 1, p. 27-55, abr. 2008. ISSN 2175-7941.

SHULMAN, L. Those who understand: Knowledge growth in teaching. Educational researcher, v. 15, n. 2, p. 4-14, 1986. ISSN 0013-189X.

SHULMAN, L. Knowledge and teaching: Foundations of the new reform. Harvard educational review, v. 57, n. 1, p. 1-23, 1987. ISSN 0017-8055.

SHULMAN, L. The signature pedagogies of the professions of law, medicine, engineering, and the clergy: Potential lessons for the education of teachers. Talk Delivered at the Math Science Partnerships (MSP) Workshop:"Teacher Education for Effective Teaching and Learning" Hosted by the National Research Council's Center for Education February, 2005. p.6-8.

SHULMAN, L. Its genesis and exodus. In: BERRY, A.; FRIEDRICHSEN, P.; LOUGHRAN, J. (Ed.). Re-examining pedagogical content knowledge in science education: Routledge, 2015. cap. 1, p. 3-13. ISBN 1317564650. 
SILVA, B. V. D. C. O desenvolvimento do conhecimento pedagógico do conteúdo referente à temática natureza da ciência na formação inicial de professores de Física. 2017. 289 f. Tese (Doutorado em Ensino de Ciências e Matemática) - Programa de Pós-Graduação em Ensino de Ciências e Matemática, Universidade Federal do Rio Grande do Norte, Natal.

SILVA, B. V. D. C.; MARTINS, A. F. P. Uma proposta para avaliação do desenvolvimento do conhecimento pedagógico do conteúdo de futuros professores de Física acerca da temática Natureza da Ciência. Caderno Brasileiro de Ensino de Física, v. 35, n. 2, p. 389-413, ago. 2018. ISSN 2175-7941.

SILVA, J. B. D.; SALES, G. L.; ALVES, F. R. V. Didática da Física: uma análise de seus elementos de natureza epistemológica, cognitiva e metodológica. Caderno Brasileiro de Ensino de Física, v. 35, n. 1, p. 20-41, abr. 2018. ISSN 2175-7941.

SOARES, S. T. C. Conhecimento Especializado de Professores de Química - CTSK: Proposta de Modelo Teórico. 2019. 88 f. Dissertação (Mestrado em Ensino) - Programa de Pós-Graduação Stricto Sensu em Ensino, Instituto Federal de Educação, Ciência e Tecnologia de Mato Grosso, Cuiabá.

TARDIF, M. Saberes docentes e formação profissional. Petrópolis, RJ: Editora Vozes Limitada, 2010. p. ISBN 8532644287.

TESTONI, L.A. Caminhos Criativos e Elaboração de Conhecimentos Pedagógicos de Conteúdo na Formação Inicial do Professor de Física. 2013. 293 f. Tese (Doutorado em Educação) - Programa de Pós-Graduação em Educação, Universidade de São Paulo, São Paulo.

VIEIRA, R. D.; MELO, V. F. D.; BERNARDO, J. R. D. R. Os procedimentos discursivos didáticos como saberes experienciais exemplares de um formador de professores de física. Caderno Brasileiro de Ensino de Física, v. 31, n. 2, p. 289-305, ago. 2014. ISSN 2175 7941.

ZIMERMANN, E.; BERTANI, J. A. Um novo olhar sobre os cursos de formação de professores. Caderno Brasileiro de Ensino de Física, v. 20, n. 1, p. 43-62, abr. 2003. ISSN $2175-7941$. 